\title{
COMPARATIVE STUDY OF LEVELS OF SELECTIVE OXIDATIVE STRESS MARKERS (MALONDIALDEHYDE, ZINC, AND ANTIOXIDANT VITAMINS A, E, AND C) IN ISCHEMIC AND NON-ISCHEMIC HEART DISEASE PATIENTS SUFFERING FROM TYPE- 2 DIABETES
}

\author{
ABD ELGADIR A ALTOUM, AHMED L OSMAN, ASAAD MA BABKER*
}

Department of Medical Laboratory Sciences, College of Health Sciences, Gulf Medical University, Ajman, UAE. Email: azad.88@hotmail.com Received: 06 June 2017, Revised and Accepted: 27 June 2018

\section{ABSTRACT}

Objective: The objective of the current study is to compare the levels of oxidative stress markers malondialdehyde (MDA), zinc, and antioxidant Vitamins (A, E, and C) in ischemic heart disease (IHD) and non-IHD patients with diabetes mellitus.

Method: This is cross-sectional study group, conducted in the advanced diagnostic center (Khartoum- Sudan) from the period May 2013 to August 2015. Comprised 100 healthy subjects were, control group with mean (fasting blood sugar) 5.61=m mol/L, the age ranged from 22 to 78 years old, the average of the age was 50.1 years. 300 patients ( 78 IHD and 222 without) as cases groups, the ages ranged from 30 to 80 years. The age average was 51.2 years, all samples were in a state of fasting for $12 \mathrm{~h}$, and the data were collected using a structured questionnaire and direct interview to collect information. Blood specimens were collected from both groups, and plasma levels of MDA, zinc, and antioxidant Vitamins (A, E, and C) were determined.

Results: There was a significant difference between the level of serum Vitamin A, E, Zinc and MDA in diabetic patients with IHD and those diabetic without IHD $(p<0.05)$. No significant differences in serum Vitamin $C$ level between both groups $(p>0.05)$.

Conclusion: Due to the significant differences in serum Vitamin A, E, Zinc, and MDA between diabetics with IHD and diabetics without IHD, these parameters can be used as prognostic markers for prediction of oxidative stress and antioxidant stress of diabetic patients with IHD complications.

Keywords: Diabetes mellitus, Ischemic heart disease, Malondialdehyde, Zinc, Vitamin C, E, and A.

(c) 2018 The Authors. Published by Innovare Academic Sciences Pvt Ltd. This is an open access article under the CC BY license (http://creativecommons. org/licenses/by/4. 0/) DOI: http://dx.doi.org/10.22159/ajpcr.2018.v11i8.27772

\section{INTRODUCTION}

Diabetes mellitus (DM) is a chronic metabolic disorder manifested in the form of hyperglycemia as a consequence of a defect in insulin secretion and/or insulin action along with an imbalance in the metabolism of carbohydrates, fats, and proteins [1]. Hyperglycemia or raised blood sugar is a common effect of uncontrolled diabetes and over time leads to serious damage to many of the body's systems, especially the nerves and blood vessels [2]. Type two DM diabetes is a major risk factor for developing macrovascular complications, including atherosclerosis, myocardial infarction, stroke, and peripheral vascular disease. In adults with diabetes, the risk of death from heart disease and stroke is 2-4 times higher than in adults without diabetes's [3]. Oxidative stress is closely associated with the pathogenesis of diabetes mellitus and results from overproduction of reactive oxygen species and overproduction is associated with hyperglycemia and metabolic disorders, such as impaired antioxidant function in conjunction with impaired antioxidant activity [4]. Apart from the traditional risk factors such as arterial hypertension, dyslipidemia, and obesity, hyperglycemia is an independent risk factor for the development of ischemic heart disease (IHD). The course of IHD in diabetic patients is usually more complicated [5]. Oxidative stress alters normal endothelial function, supporting pro-inflammatory, prothrombotic, proliferative, and vasoconstrictor mechanism that favors the development of atherosclerosis and vascular tissue injury. The pathogenesis of atherosclerosis involves damage to the capillary endothelium caused by various factors including oxidized lowdensity lipoprotein [6]. The aim of the current study was to evaluate and compare the levels of oxidative stress markers malondialdehyde (MDA), zinc, and antioxidant Vitamins (A, E, and C) in IHD and non-IHD patients with DM.

\section{METHOD}

This study was conducted in Khartoum state in the advanced diagnostic center from the period May 2013 to August 2015. 100 healthy subjects were control group with mean fasting blood sugar (FBS) $5.61=\mathrm{m} \mathrm{mol} / \mathrm{L}$. The age ranged from 22 to 78 years old. The age average was 50.1 years. Type 2 diabetic patients were 300 (78 IHD and 222 without), the ages ranged from 30 to 80 years old. The age average was 51.2 years. All samples were collected after $12 \mathrm{~h}$ fasting. MDA in serum performed by mixing with $20 \%$ trichloroacetic acid and incubated for $10 \mathrm{~min}$. After that $0.05 \mathrm{ml}$ of $\mathrm{H}_{2} \mathrm{So}_{4}$ and thiobarbituric acid were added. The mixture was mixed and place in $70^{\circ} \mathrm{C}$ water bath for $30 \mathrm{~min}$. The resulting chromogen was extracted with n-butanol and centrifuged at $2000 \mathrm{rpm} /$ min, and measured against butanol blank at $532 \mathrm{~nm}$ excitation and $553 \mathrm{~nm}$ emission by spectrophotometer. The antioxidant Vitamins (A, C, $\mathrm{E}$, and Zinc) were assayed by high-performance liquid chromatography. In the samples, the peak height (area) ratio was determined, and the appropriate plasma retinol (Vitamin A) and the appropriate plasma tocopherol (Vitamin E) concentrations were determined from the standard curve (regression line formula, Vitamin A and E were detected at $290 \mathrm{~nm}$. The Vitamin C was identified by comparing the retention time of the sample peak with that of the Vitamin C standard at $245 \mathrm{~nm}$. Zinc present in the sample is chelated by 5-Br-PAPS 2-(5-bromo-2pyridylazo)-5-(N-propyl- $\mathrm{N}$-sulfopropylamino)-phenol in the reagent. The formation of this complex is measured at a wavelength of $560 \mathrm{~nm}$ [7]. The study was approved by in advanced diagnostic center, in Khartoum. All samples were taken from the participants after they agreed and fill the questionnaire. Statistical Package for the Social Sciences (version 13) computer software was used for data analysis. The means and standard deviations of a variable calculated and t-test were used for comparison (significant level was set at $\mathrm{p} \leq 0.05$ ). 
Table 1: Baseline characteristics of the respondents and comparison of the means of blood parameters between diabetics and none diabetics

\begin{tabular}{lll}
\hline Variables & Control (none-diabetics) (n=100) & Test group (diabetics) (n=300) \\
\hline Age (years) & $50.1 \pm 14.0$ & $51.2 \pm 11.1$ \\
(Max-Min) & $(22.0-78.0)$ & $(23.0-80.0)$ \\
Weight (kg) & $74.5 \pm 12.2$ & $79.7 \pm 22.8$ \\
(Max-Min) & $(52.0-105.0)$ & $(50.0-180.0)$ \\
Height (m) & $171 \pm 10.0$ & $164 \pm 10.0$ \\
(Max-Min) & $(152-196)$ & $(135-190)$ \\
FBS & $101.5 \pm 11.9$ & $160.4 \pm 65.5$ \\
(Max-Min) & $(70.0-120.0)$ & $(75.0-480.0)$ \\
Vitamin A & $81.2 \pm 21.8$ & $50.3 \pm 20.0$ \\
(Max-Min) & $(10.0-133.0)$ & $(14.0-95.0)$ \\
Vitamin E & $15.6 \pm 4.8$ & $5.2 \pm 1.8$ \\
(Max-Min) & $(3.5-24.0)$ & $(1.0-9.0)$ \\
Vitamin C & $10.0 \pm 2.2$ & $3.9 \pm 1.3$ \\
(Max-Min) & $(4.6-18.0)$ & $(1.2-6.9)$ \\
MDA & $2.4 \pm 1.1$ & $6.7 \pm 6.2$ \\
(Max-Min) & $(1.0-12.0)$ & $(1.0-35.0)$ \\
Serum Zinc & $(100.5 \pm 12.9) \mu g / l$ & $0.0002^{*}$ \\
(Max-Min) & & $0.001^{*}$ \\
\hline
\end{tabular}

*Significant differences in weight, height, serum Vitamin A, C, E, FBS, Zinc, and MDA between control and test group (p<0.05). ${ }^{* *}$ No significant differences in age. MDA: Malondialdehyde, FBS: Fasting blood sugar

\section{RESULTS}

The general characteristics of the subjects (case and control) included in the study are listed in Table 1. There is no significant difference in age between the two groups age mean \pm standard deviation (SD) was $50.1 \pm 14.0$ for the control group versus $51.2 \pm 11.1$ for the test group $(\mathrm{p}=0.06)$. Weight and height showed significant differences between the test and control group. Weight Mean $\pm S D$ was $74.5 \pm 12.2 \mathrm{~kg}$ for the control group and $79.7 \pm 22.8 \mathrm{~kg}$ for the test group ( $\mathrm{p}=0.032$ ). Height Mean \pm SD was $171 \pm 10.0 \mathrm{~cm}$ for the control group and was $164 \pm 10.0$ for the test group ( $\mathrm{p}=0.0006)$. Shows a highly significant difference between the mean of test group ( $\mathrm{n}=300)$ and the mean of control group $(n=100)$ in FBS Mean \pm SD: $(160 \pm 65.5)$ versus $(101 \pm 11.9) \mathrm{mg} / \mathrm{dl}$, respectively $(\mathrm{p}=0.002)$, Serum vitamin A ,Mean \pm SD: $(50.3 \pm 20.0)$ versus $(81.2 \pm 21.8) \mu \mathrm{g} / \mathrm{dl}$, respectively $(\mathrm{p}=0.001)$, serum vitamin E Mean \pm SD: $(5.2 \pm 1.8)$ versus $(15.6 \pm 4.8) \mu \mathrm{g} / \mathrm{ml}$, respectively $(p=0.001)$,serum vitamin C , Mean \pm SD: $(3.9 \pm 1.3)$ versus $(10 \pm 2.2) \mu \mathrm{g} / \mathrm{ml}$, respectively $(\mathrm{p}=0.0003)$ and plasma MDA ,Mean \pm SD: $(6.7 \pm 6.2)$ versus $(2.4 \pm 1.1) \mathrm{n} \mathrm{mol} / \mathrm{l}$, respectively $(\mathrm{p}=0.001)$ and Serum zinc Mean \pm SD: $(77.2 \pm 9.8)$ versus $(100.5 \pm 12.9) \mu \mathrm{g} / \mathrm{l}$, respectively $(\mathrm{P}=0.001)$.

78 of the test group (26\%) have IHD, whereas 222 of them $74 \%$ have no heart disease. A significant difference between the means of serum Vitamin A of the test group with IHD $(\mathrm{n}=78)$ and those without IHD $(\mathrm{n}=222)$. Mean \pm SD: $45.8 \pm 21.6$ versus $51.9 \pm 19.2 \mu \mathrm{g} / \mathrm{dl}$, respectively $(\mathrm{p}=0.022)$. A significant difference between the means of serum Vitamin $\mathrm{E}$ in the test group with IHD $(\mathrm{n}=78)$ and those without IHD $(\mathrm{n}=222)$. Mean \pm SD: $4.8 \pm 1.8$ versus $5.3 \pm 1.8 \mu \mathrm{g} / \mathrm{ml}$, respectively $(\mathrm{p}=0.023)$. Insignificant difference between the means of serum Vitamin $C$ in the test group with IHD $(n=78)$ and those without IHD $(n=222)$. Mean \pm SD: $3.8 \pm 1.3$ versus $4.0 \pm 1.3 \mu \mathrm{g} / \mathrm{ml}$, respectively $(\mathrm{p}=0.234)$. A significant difference between the means of plasma MDA of the test group with IHD $(n=78)$ and those without IHD $(n=222)$. Mean \pm SD: $12.2 \pm 8.5$ versus $4.8 \pm 3.6 \mathrm{n} \mathrm{mol} / \mathrm{l}$, respectively $(\mathrm{p}=0.04)$. A significant difference between the means of serum zinc of the test group with IHD $(n=78)$ and those without IHD $(\mathrm{n}=222)$. Mean \pm SD: $75.4 \pm 10.3$ versus $77.9 \pm 9.5 \mu \mathrm{g} / \mathrm{l}$, respectively $(\mathrm{p}=0.05)$ (Table 2 ).

\section{DISCUSSION}

In the present study, we have determined the main oxidative stress markers among diabetic patients with IHD complication and non-IHD. Our results showed that serum MDA is a highly significant difference between the means of serum MDA of patients with IHD and the patient's group without heart disease. This concept is analogous to that described by Shabana and Steve, observed significantly different blood
Table 2: Comparison of blood parameters among test group according to IHD

\begin{tabular}{llll}
\hline Variables & IHD N (78) & Non-IHD N (222) & p \\
\hline FBS & $159.0 \pm 54.2$ & $160.9 \pm 69.2$ & $0.822^{* *}$ \\
(Max-Min) & $(86.0-326.0)$ & $(75.0-480.0)$ & \\
Vitamin A & $45.8 \pm 21.6$ & $51.9 \pm 19.2$ & $0.022^{*}$ \\
(Max-Min) & $(15.0-92.0)$ & $(14.0-95.0)$ & \\
Vitamin E & $4.8 \pm 1.8$ & $5.3 \pm 1.8$ & $0.023^{*}$ \\
(Max-Min) & $(1.9-8.9)$ & $(1.0-9.0)$ & \\
Vitamin C & $3.8 \pm 1.3$ & $4.0 \pm 1.3$ & $0.234^{* *}$ \\
(Max-Min) & $(1.2-6.9)$ & $(1.2-6.8)$ & \\
MDA & $12.2 \pm 8.5$ & $4.8 \pm 3.6$ & $0.04^{*}$ \\
(Max-Min) & $(1.2-35.0)$ & $(1.0-20.0)$ & $0.05^{*}$ \\
Zinc & $75.4 \pm 10.3$ & $77.9 \pm 9.5$ & \\
(Max-Min) & $(55.0-95.0)$ & $(55.0-95.0)$ & \\
\hline
\end{tabular}

*Significant differences in Serum Vitamin A and E, Zinc, MDA between diabetics with ischemic heart disease and diabetics without ischemic heart disease $(\mathrm{p}<0.05)$. **No significant differences in Serum Vitamin $\mathrm{C}$ and FBS ( $p>0.05)$. MDA: Malondialdehyde, FBS: Fasting blood sugar, IHD: Ischemic heart disease

levels of MDA among patients with chronic heart disease which were indicating overall oxidative stress in those patients [8]. This result also is consistent with another study conducted by Khan, and Abdul Baseer reported that the elevated serum levels of MDA indicate an increase in the level of production of oxygen free radicals, suggesting their possible role in atherogenesis, leading to coronary heart disease $[9,10]$. The results of the study also indicated a highly significant increase in the levels of serum antioxidant Vitamins A and E of patients with IHD and the patient's group without heart disease. Our findings are in agreement with those of other authors who showed serum Vitamin A and Vitamin E levels in patients with chronic heart disease were found to be lower than without heart disease [11-13]. On the other hand, some reports indicate that no significant changes occur in patients with heart disease when compare to patients without heart disease $[14,15]$. Reduced levels of Vitamin E may also be due to the increased requirement of Vitamin E in pro-oxidant milieu with enhanced free radical status, leading to the increased lipid peroxidation, a resultant depletion of free radical scavenger, and antioxidant reserves of the body [16]. The findings showed that there is no significant change between the means of serum Vitamin C in the test group with IHD and those without IHD. Our finding supported by some cohort studies and randomized trials have shown no relationship between Vitamin C intake and heart disease risk $[17,18]$. The results disagreed with many studies reported that 
there was significant association between Vitamin C and chronic heart disease $[19,20]$. Our results showed that serum zinc is a significant difference between the means of serum zinc of patients with IHD and the patient's group without heart disease. Our finding is supported by many results indicate that there is a significant association between low serum zinc levels and heart disease [21,22]. On the other hand, in large cohort conducted among type 2 diabetic patients, concluded that low serum zinc level was an independent risk factor for heart disease events [23]. Furthermore, Soinio et al. concluded that low serum levels of zinc can be an independent risk factor of coronary artery disease. Low serum $\mathrm{Zn}$ levels in the IHD patient group may be related to excess release of steroids due to the release of leukocyte endogenous mediators which redistribute the body $\mathrm{Zn}$ from serum and may cause a drop in serum $\mathrm{Zn}$ and also due to elevated levels of $\alpha_{2}$-macroglobulin which is a transport protein containing large amounts of $\mathrm{Zn}[24,25]$. The limitations of the study included relatively small sample size (seventy-eight) diabetic patients with IHD and inability to include more biochemical and anthropometric measures such as, glutathione, and glycerophospholipids to observe the real oxidative stress change as a complication of heart disease. The findings of this study should be replicated in larger cohorts in the future with more oxidative stress parameter and also include sex, ethnic, smoking, dietary habits, and family history.

\section{CONCLUSION}

This study shows that antioxidant status is impaired in diabetics patients with IHD compared to diabetic patients without IHD. Significant differences in serum Vitamin A, E, Zinc, and MDA between diabetics with IHD and diabetics without IHD can be used (A, E, Zinc, and MDA) as prognostic markers for prediction of oxidative stress and antioxidant stress of diabetic patients with IHD complications.

\section{ACKNOWLEDGMENT}

We are grateful to them all for participating in our study and special thanks to the staff of advanced diagnostic center for routine follow-up in Sudan.

\section{AUTHOR'S CONTRIBUTION}

There are no conflicts of interests between authors; all three authors have made substantial contributions to conception and design, analysis, and interpretation of data. All authors have participated in drafting and revising the article and have given their final approval for submission.

\section{REFERENCES}

1. Jayesh BD, Snehal NM, Archana RJ. Diabetic nephropathy-genesis, prevention and treatment. Int J Pharm Pharm Sci 2014;6:42-7.

2. World Health Organization. Global Report on Diabetes. Geneva: World Health Organization; 2016.

3. Bartels DW, Davidson MH, Gong WC. Type 2 diabetes and cardiovascular disease: Reducing the risk. J Manag Care Spec Pharm 2007;13:1-7.

4. Kayama Y, Raaz U, Jagger A, Adam M, Schellinger IN, Sakamoto M, et al. Diabetic cardiovascular disease induced by oxidative stress. Int J
Mol Sci 2015;23:25234-63.

5. Dresslerova I, Vojacek J. Diabetes mellitus and ischemic heart disease. Vnitrni Lekarstvi 2010;56:301-6.

6. Singh K, Sukhjit K, Rajiv A. status of certain oxidative stress markers in ischemic heart disease patients with and without smoking in north Indian Punjabi population. Br Biomed Bull 2015;3:225-31.

7. Elgadir AA, Ahmed LO, Ma BA. Correlation of oxidative stress markers malondialdehyde (MDA), antioxidant vitamins A, E, and C with glycated hemoglobin (HBA1C) levels in Type 2 diabetes mellitus. Asian J Pharm Clin Res 2018;5:281-3.

8. Shahid SU, Humphries S. The SNP rs10911021 is associated with oxidative stress in coronary heart disease patients from Pakistan. Lipids Health Dis 2018;17:6.

9. Khan MA, Baseer A. Increased malondialdehyde levels in coronary heart disease. J Pak Med Assoc 2000;50:261-4.

10. Najah AL, Al-kaissi E, Muhi-eldeen ZA, Arafat TA, AL-Muhtaseb SI. Oxidants and antioxidants as risk factors in young Arabian male patients with acute myocardial infarction. Int J Pharm Pharm Sci 2016;8:273-7.

11. Yıldıran H, Mercanlıgil SM, Besler HT, Tokgözoğlu L, Kepez A. Serum antioxidant vitamin levels in patients with coronary heart disease. Int J Vitam Nutr Res 2011;81:211-7.

12. Schroder S. Is supplementation with antioxidants effective in the treatment of atherosclerosis? Med Wochenschr 2004;129:321-6.

13. Riccioni G, Frigiola A, Pasquale S, de Massimo G, D’Orazio N. Vitamin $\mathrm{C}$ and $\mathrm{E}$ consumption and coronary heart disease in men. Front Biosci 2012;4:373-80

14. Rajasekhar D, Rao PS, Latheef SA, Saibaba KS, Subramanyam G. Association of serum antioxidants and risk of coronary heart disease in South Indian population. Indian J Med Sci 2004;58:465.

15. Dube A, Khalsa A, Gupta SK, Singh U, Sharma P. Serum tocopherol and lipids in patients with coronary artery disease. Ind Heart J 1998;50:292-4.

16. Randall A, Swain, Machlis BK, Pharma D. Therapeutic uses of vitamin $\mathrm{E}$ in prevention of atherosclerosis. Altern Med Rev 1999;4:414-23.

17. Moser MA, Chun OK. Vitamin $C$ and heart health: A review based on findings from epidemiologic studies. Int J Mol Sci 2016;17:1328.

18. Lee DH, Folsom AR, Harnack L, Halliwell B, Jacobs DR. Does supplemental vitamin $\mathrm{C}$ increase cardiovascular disease risk in women with diabetes? Am J Clin Nutr 2004;80:1194-200.

19. Institute of Medicine. Dietary Reference Intakes for Vitamin C, Vitamin E, Selenium, and Carotenoids. Washington, DC, USA: The National Academies Press; 2000.

20. Desai CK, Huang J, Lokhandwala A, Fernandez A, Riaz IB, Alpert JS. The role of vitamin supplementation in the prevention of cardiovascular disease events. Clin Cardiol 2014;37:576-81.

21. Yu X, Huang L, Zhao J, Wang Z, Yao W, Wu X, et al. The relationship between serum zinc level and heart failure: A Meta-analysis. Biomed Res Int 2018;2018:2739014.

22. Demirbag R, Yilmaz R, Erel O, Gultekin U, Asci D, Elbasan Z, et al. The relationship between potency of oxidative stress and severity of dilated cardiomyopathy. Can J Cardiol 2005;21:851-5.

23. Soinio M, Marniemi J, Laakso M, Pyörälä K, Lehto S, Rönnemaa T, et al. Serum zinc level and coronary heart disease events in patients with Type 2 diabetes. Diabetes Care 2007;30:523-8.

24. Almzaiel AJ. Oxidative stress and inflammation in ischemic heart disease: Role of trace elements, oxidants and antioxidants. J Contemp Med Sci 2015;1:18-27.

25. Shekokar DP, Kaundinya D. Effect of acute myocardial infarction on serum zinc level. Indian J Basic Appl Med Res 2013;3:80-7. 